\title{
PFDA- FMEA. An integrated method improving FMEA assessment in Product Design
}

Pedro A. Garciaa, ${ }^{a}$, Luis Perez-Dominguez ${ }^{a, 2}$, David Luviano-Cruz ${ }^{a, 3}$, Jesus Jaime Solano Noriega ${ }^{b, 4}$, Erwin Martinez Gomez $^{\mathrm{a}, 5}$, Mauro Callejas-Cuervo ${ }^{\mathrm{c}, 6}$

aDepartamento de ingeniería Industrial y Manufactura, Universidad Autónoma de Ciudad Juárez, Ciudad Juárez, Chihuahua, México

bDepartamento Ciencias Económico-Administrativa, Universidad Autónoma de Occidente, Culiacán, México

'Universidad Pedagógica y Tecnológica de Colombia, Tunja, Boyaca, Colombia

${ }^{1}$ Pedro A. Garcia peagarci@gmail.com ORCID: 0000-0002-4922-0560

${ }^{2}$ Dr. Luis Pérez-Domínguez luis.dominguez@uacj.mx ORCID: 0000-0003-2541-4595

${ }^{3}$ Dr. David Luviano-Cruz david.luviano@uacj.mx ORCID: 0000-0002-4778-8873

${ }^{4}$ Dr. Jesús Jaime Solano Noriega jaime.solano@uadeo.mx ORCID: 0000-0002-8762-1453

${ }^{5}$ Dr. Erwin Martínez Gómez emartine@uacj.mx ORCID: 0000-0002-7753-2545

${ }^{6}$ Mauro Callejas-Cuervo, mauro.callejas@uptc.edu.co, ORCID: 0000-0001-9894-8737

\begin{abstract}
:
Product Design is getting nowadays new challenges on developing new products, since the industry is in a rush to introduce products into the marketplace, where customers demand products faster, cheaper, and free of failures. In the meantime, global companies are always trying to improve their Product Design process to get advantages over their competitors using proven tools like FEMA and mixing methodologies like Fuzzy theories with FMEA. Even today using all this tools and combination of methodologies there is a gap to address and it is required a robust risk analysis solving current issues in the electronic industry. This document aims to reveal a novel integrated method, where Failure Mode and Effect Analysis, Pythagorean Fuzzy Sets and Dimensional Analysis are cohesive into a model that minimize the uncertainty of the ranking and prioritization over the Failure Mode and Effect Analysis execution, helping to identify risks within an accurate grade over possible failures in the Product Design process. A real practical example is used to show the proposed method, where it is identified a robust methodology integration and solid and results using a sensitivity analysis.
\end{abstract}

Key words: Product Design (PD), Failure Mode and Effect Analysis (FMEA), Dimensional Analysis (DA), Pythagorean Fuzzy Sets (PFS).

\section{Introduction}

Product Design (PD) maintains the market dynamic as well as moves the global economies because the companies around the world are putting into the marketplace different products for consumers around the globe, [1]. PD is a complex and usually long process, involving a cross-functional team and trying to solve to perform multiple activities, [2]. All the complexity of this process adds a lot of uncertain on the different PD phases. Kahn [1], analyzed the formality of the PD process on different companies around the world, and it is a continues effort to improve the PD process, some authors are putting together more than one methodology with the objective to reinforce the PD process. Susanto and Andriana [3], used Quality Function Deployment (QFD) to analyze PD, other authors mix methodologies, like Yang and Huang, they used TRIZ and Fuzzy sets in [4], in the intent to make robust the PD process. 
Failure Mode and Effect Analysis (FMEA) is now a sustained tool which allows to analyze the risk of possible impact on any process, since the proposal of this tool it was rapidly adapted to different industries like automotive and electronics, and it is continuously being improved since that time. One of the main improvement on the FMEA, which is used until nowadays, is the Risk Priority Number (RPN) first introduced by Braband, [5]. Usually the FMEA is ranked by experts on the process under analysis, the RPN is the product ranked of three values, from 1 to 10 , the three values are the Severity (S), Occurrence (O), and Detection (D), the final value of the RPN rank the critical potential failure modes (PFMs) on the process analyzed, helping to take the decision if the possible failure mode is a risk or no then, based on the previous range stablished of the RPN value, contingency plans have to be apply to avoid the risk of the possible failure.

FMEA is a useful tool identifying risks on multicriteria problems however, the FMEA has a weakness identified by some authors like Fang et al [6], they pinpoint the uncertainty when the RPN value is the same, and the factors $\mathrm{S}, \mathrm{O}$ and $\mathrm{D}$ have a different order. Besides the different opinions, FMEA is a popular tool used to identify product risks before, during, and after the PD process, moreover applying new techniques to this tool is also common to improve the outputs, like FMEA and Multi-Criteria integrated by Lui et al [7], then many authors combine methods to improve specific processes, like Pillay and Wang [8], who used the FMEA with grey relational theory to correct the same FMEA flaw on the RPN. Zhou and Thai [9], use fuzzy and grey theories to predict the failure in a practical example. Safari et al [10] applied fuzzy VIKOR technique to the FMEA to evaluate enterprise architecture risks. Pun et al [11], applied Fuzzy Integrated FMEA to NPD process in flexible electronics field. MCDM based on TOPSIS Fuzzy [12]. Khalilzadeh et al [13], applied Best Worst Method and GRA-VIKOR mixed with fuzzy logics methods, suggesting a new FMEA version.

Fuzzy Logic is another important topic included in the proposed method on this document. Fuzzy sets was introduce by Zadeh since 1965, [14], fuzzy logic accepts error and mixed data as an input, giving an accurate output. Intuitionistic Fuzzy Sets (IFS) first time documented by Atanassov in 1986 [15], then Pythagorean Fuzzy Sets (PFS) introduced by Yager in 2014 [16], he mentioned that PFS helps to manage error and the uncertainty on the input data, eradicating ambiguity and bias, getting better output. Wichmann et al [17], used Fuzzy sets to minimize the uncertain on the PD project schedule.

Different Multi-criteria problems was faced by using Dimensional Analysis (DA) in a combination of the PFS, as per Perez-Dominguez et al [18], Recently Mahoney and Yeralan [19], documented different examples of the use of the DA. According DA has advantages to solve multi-criteria problems used in combination with Fuzzy Logic. Shen et al [20], analyzed the applications of the DA over the statistics.

Product Design is a complex process which have multiple different problems to solve during the different design phases [21], the risk analysis is essential during all the PD process, [22] and beside the multiple problems to solve, we also have some gaps in the tools that we use to solve those problems, that is the case of the FMEA tool. There are cracks identified over the FMEA assessment [23]. As a summary of the main FMEA identified gaps are as per next list based on Mzougui and Felsoufi [24], Huang et al [23].

- Ambiguity while the factors $S, O$, and $D$ showed the same RPN value in having different orders.

- Difficulty to get a consensus for RPN because of ranking by multiple disciplines experts.

- Uncertainty over the FMEA inputs since the different judgment of the experts assessing the FMEA.

- Vagueness due to the crossed opinions on the cross-functional team assessing the FMEA. 
- Polarizing the decision to choose the risks impacting PD process, when assume the high severity is the high risk.

Today there are different methodologies applied to the PD process for risk assessment and design optimization as we discussed in the introduction, even thought, there is not an integral model like the proposed methodology in this paper, PFDA-FMEA, which uses key methodologies to remove the FMEA RPN uncertain issue and gaps mentioned earlier and helps to identify and rank the risks in an accurate and simple way.

Due to the importance of the PD process, and to cover the gaps in the FMEA tool, this PFDA-FMEA method integrates FMEA, PFDA, this specific integration is intended to improve the FMEA for PD process on the decision making based on the FMEA assessment. The proposed methodology PFDA-FMEA is demonstrated using a real practical example, showing step by step the methodology, PFDA-FMEA.

This document is structured as follows: Section 2 describes the basic concepts on each of the different methodologies used in the proposed PFDA-FMEA method. Subsequently, Section 3 is showing the methodology PFDA-FMEA step by step, eased from the using of a practical real example, then following Section 4, revels the details on the calculus performed in a detailed step by step, therefore the results in Section 5 and finally Section 6 includes the discussion and conclusions of this document.

\section{Basic Concepts}

\subsection{FMEA}

FMEA method is a well know tool in different industries to detect possible risks in a process under study, detailed FMEA methodology is described by the Automotive Industry Action Group (AIAG) [25]. FMEA assessment starts identifying the potential failure modes in the process under analysis, then a team of experts in the problem of study evaluates three risk factors for the potential failures modes: i) severity (S); ii) the occurrence (O); and iii) the detection (D). Finally, the product of $S, O$, and $D$ generates the RPN [5]. Full details of the method are described by the Automotive Industry Action Group (AIAG) [25]. The FMEA assessment continues in rows as long as PFMs are identified, and the highest RPNs point to the highest risk on the analysis.

\subsection{Pythagorean Fuzzy Sets}

Yager introduced PFS [26], used in this document and defined as following.

Definition. Per Zhang and Xu [27], Yang and Hussain [28], X is representing the universe then a PFS P in X is given by:

$P=\left\{\left\langle x, \mu_{p}(x), v_{p}(x)\right\rangle \mid x \in X\right\}$

Where $\mu_{p}(x): X \rightarrow[0,1]$ defines the degree of membership and $v_{p}(x): X \rightarrow[0,1]$ defines the degree of non-membership of the element $x$, where $x \in X$ to $P$.

Definition. According Zhang and Xu [27], for any PFS, $p=(\mu, v), p$ is defined as follows:

$$
s(p)=(\mu)^{2}-(v)^{2}(2)
$$

Where $s(p) \in[-1,1]$ 


\subsection{Pythagorean Fuzzy Dimensional Analysis}

Pythagorean Fuzzy Dimensional Analysis PFDA is used in the practical example before the FMEA assessment, where it is also required an extra step to assess the FMEA based on the linguistic values, then the results are ranked, this will help to have a clear path to identify what are the main PFS affecting the PD process. PFDA is applied to normalize the inputs and allowing to use mixed data, qualitative and quantitative, coming from the FMEA allowing the information to be comparable even if we have mixed data types in the FMEA inputs. Villa et al. [29], integrates PFS and DA using the equation 1, they used PFS and DA to solve a multicriteria decision problem.

$$
\begin{array}{r}
\text { Pythagorean fuzzy Index of Similarity integrated by Villa et al. [29]. } \\
\operatorname{PFIS} S_{i}\left(\omega_{1}^{i}, \omega_{2}^{i}, \ldots, \omega_{m}^{i}\right)=\left(\prod_{k=1}^{n}\left(\mu_{\xi_{j}^{i}}\right)^{T_{j}}, \sqrt{1-\prod_{k=1}^{n}\left(1-\left(v_{\xi_{j}^{i}}\right)^{2}\right)^{T_{j}}}\right)(3)
\end{array}
$$

Where:

$\mathrm{PFIS}_{\mathrm{i}}=$ Pythagorean fuzzy Index of Similarity, for $i=1,2, \ldots, m$

$\omega=$ Pythagorean sets, $\mu=$ Membership values assigned, and $\nu=$ Values of $\mathrm{S}, \mathrm{O}$ and $\mathrm{D}$

Then:

$T_{j}=$ Weights assigned to the experts, for $j=1,2, \ldots, m, k=1,2, \ldots, \mathrm{n}$, and $\xi=$ universe of considered elements

$\mathrm{T}_{j} \in[0,1]$, index $i$ defined by the PFS.

\section{FMEA-PFDA approach}

The proposed PFDA-FMEA method uses FMEA as a basis to collect and organize the main PFMs over the process to be analyzed by the SME group, then the PFDA method is applied. The suggested method is generalized in the five steps below and illustrated in Figure 1.

Step 1. Creation of SMEs group. Depending on the process to assess, it is required to identify a group of $n$ experts on the matter to be assessed, to perform the assessment.

Step 2. Assign weights to SME. Once the SME group is selected, a weight is assigned to each of the experts, the weight to each SME can be assigned depending on the grade of expertise on the matter under analysis. Step 3. SME group identify PFMs. The group of experts agree and stablish the main internal and external characteristics that affect direct or indirect the process under analysis.

Step 4. Assess FMEA using Linguistic Values. The list of PFMs is evaluated by each SME independently and based on their experience on the matter, using Table 1 to assign the corresponding Linguistic Values. 
Table 1.Linguistic Values for PFDA, Membership and Non-Membership Functions.

\begin{tabular}{lcc}
\hline \multicolumn{1}{c}{ Linguistic expressions } & $\begin{array}{c}\text { Membership } \\
\text { Function }(\mu \xi)\end{array}$ & $\begin{array}{c}\text { Non-Membership } \\
\text { Function }(\nu \xi)\end{array}$ \\
\hline Low affectation to quality (LQ) & 0.15 & 0.95 \\
Regular affectation to quality (RQ) & 0.55 & 0.55 \\
High affectation to quality (HQ) & 0.80 & 0.20 \\
Low affectation on time (LT) & 0.35 & 0.85 \\
Regular affectation to time (RT) & 0.45 & 0.55 \\
High affectation to time (HT) & 0.95 & 0.10 \\
Low affectation to budget (LB) & 0.20 & 0.75 \\
Regular affectation to budget (RB) & 0.45 & 0.45 \\
High affectation to budget (HB) & 0.75 & 0.25 \\
Low affectation to market (LM) & 0.25 & 0.95 \\
Regular affectation to market (RM) & 0.50 & 0.50 \\
High affectation to market (HM) & 0.85 & 0.15
\end{tabular}

Step 5. Computing and obtain PFDA-FMEA. The results obtained in the previous step are used to apply PFDA per equations 3 , then using equation 2 the values are defuzzify getting the PFDA-FMEA results for $\mathrm{S}, \mathrm{O}$, and $\mathrm{D}$.

Step 6. Obtain the PFDA-FMEA index. The mathematical product of PFDA-FMEA S, O, and D, is giving us the PFDA-FMEA index.

Step 7. Determine the PFM ranking. The results are ranked to identify the PFM risks and to support on the decision to be taken.

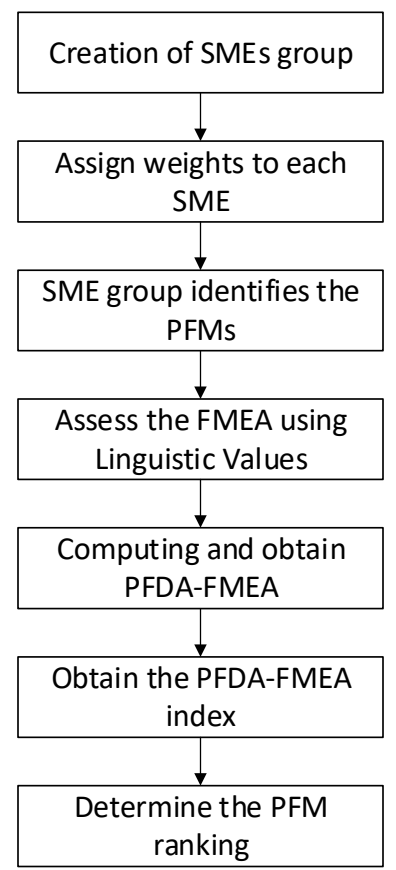

Figure 1.PFDA-FMEA Methodology step by step diagram. 


\section{Numerical case}

PD in the different industries at the present time, identifies challenges for risks assessment. This integrated methodology PFDA-FMEA, will bridge these identified gaps, and helps to have a clear view at the time to identify the main risks during the PD process.

As a practical real case is presented in this document, to exemplify and validate the PFDA-FMEA methodology. The example is based on an electronic device new product design scenario, and the group of SMEs are engineering closed connected with the electronic design product process. A risk assessment is required thru all the Product Design to avoid failures on the product and complete the design on time within the customer specifications, this example shows the PFDA-FMEA assessment at the very beginning of the first stage of the project. PFDA-FMEA helps on getting a clear view of the impact of the risks associated to the electronic device product design process and help to take the right decision on where to apply more resources to avoid the impact of the risks identified.

The proposed PFDA-FMEA method uses FMEA as a base of this methodology, FMEA helps to collect and organize the main PFMs over the PD process by the SME group for the practical real example on this document. Then PFDA is applied with the intention to minimize the uncertain on the human decision taken on the ranking of S, O and D. PFDA is as per Equation 1 by [16], [18], [28].

Step 1. Creation of SMEs group. A group of three experts on electronic devices Product Design is tied together, the Subject Matter Experts are numbered in a sequence as SME 1, SME 2, and SME 3.

Step 2. Assign weights to SME. Weights are assigned to each SME member, the values of the weights are assigned equally to each SME for this practical example, giving $1 / 3$ to be in accordance to the total value between 0 to 1 .

Step 3. SME group identify PFMs. The SMEs group on electronic devices PD process suggests the PFMs that impact direct or indirect the performance of the PD on first stages of the process. From this practical example the SMEs group agree to use the 19 PFMs in the Table 2.

Table 2. Product Design Main Potential Failure Modes identified by SME group.

\begin{tabular}{cl}
\hline PFM ID & \multicolumn{1}{c}{ Potential Failure Mode } \\
\hline PFM1 & Extremely limited time to launch \\
PFM2 & Customer requirements change \\
PFM3 & Lack of consideration for aesthetic \\
PFM4 & Technical failures on the product \\
PFM5 & Last minute design changes \\
PFM6 & Product low performance \\
PFM7 & Manufacturing not ready for launch \\
PFM8 & Lack of manufacturing capacity \\
PFM9 & Material long lead times \\
PFM10 & Potential Market saturated \\
PFM11 & Pilot runs failures \\
\hline
\end{tabular}




$\begin{array}{ll}\text { PFM12 } & \text { Failure on customer samples } \\ \text { PFM13 } & \text { Lack of inventory for launch } \\ \text { PFM14 } & \text { Wrong market analysis } \\ \text { PFM15 } & \text { No tech available for development } \\ \text { PFM16 } & \text { Environmental compliance not considered } \\ \text { PFM17 } & \text { New tech on manufacturing process } \\ \text { PFM18 } & \text { Lack of experts for develop the product } \\ \text { PFM19 } & \text { Bad quality on raw material }\end{array}$

Step 4. Assess FMEA using Linguistic Values. The Linguistic Values in Table 1 are used to assess the FMEA. SMEs group performs the FMEA assessment using the Linguistic Values instead of the regular FMEA scale to assess the $\mathrm{S}, \mathrm{O}$ and $\mathrm{D}$. This step pretends to manipulate the uncertain on the evaluation process since the human judgement. Table 3 shows the results of this step.

Table 3. SMEs FMEA assessment summary using Linguistic Values.

\begin{tabular}{c|ccc|ccc|ccc}
\hline & & S & & & O & & D \\
PFM ID & SME1 & SME2 & SME3 & SME1 & SME2 & SME3 & SME1 & SME2 & SME3 \\
\hline PFM1 & HT & RT & RT & RT & RT & LT & HT & RT & RT \\
PFM2 & RT & RT & LT & RT & RT & LT & HT & HT & RT \\
PFM3 & RM & LM & RM & RM & RM & LM & HM & RM & RM \\
PFM4 & HB & RB & HB & LB & LB & RB & LB & RB & LB \\
PFM5 & RT & HT & HT & RT & RT & RT & RT & RT & RT \\
PFM6 & HQ & RQ & HQ & RQ & RQ & LQ & HQ & RQ & RQ \\
PFM7 & RT & RT & LT & RT & LT & LT & RT & RT & LT \\
PFM8 & RM & LM & RM & RM & LM & LM & RM & LM & RM \\
PFM9 & RT & RT & LT & RT & RT & LT & LT & LT & LT \\
PFM10 & LM & LM & RM & HM & RM & RM & RM & LM & RM \\
PFM11 & RT & LT & RT & LT & RT & LT & LT & RT & LT \\
PFM12 & RQ & HQ & RQ & RQ & LQ & RQ & HQ & RQ & RQ \\
PFM13 & LT & LT & LT & RT & LT & RT & RT & RT & RT \\
PFM14 & HM & RM & HM & RM & RM & LM & HM & RM & HM \\
PFM15 & LT & LT & RT & RT & RT & RT & RT & LT & LT \\
PFM16 & LT & RT & LT & RT & LT & LT & LT & LT & RT \\
PFM17 & HT & RT & RT & RT & RT & LT & RT & LT & RT \\
PFM18 & RT & LT & RT & RT & RT & LT & LT & RT & RT \\
PFM19 & LQ & RQ & LQ & LQ & LQ & RQ & RQ & LQ & LQ \\
\hline
\end{tabular}

Step 5. Computing and obtain PFDA-FMEA. PFDA is applied to the assessment results, by using Equation 3 , then the Equation 2 this last equation to defuzzify the fuzzy numbers and to obtain crisp values. The computation results are at Table 4, getting the values for $S, O$, and D on the PFDA-FMEA. 
Table 4. PFDA-FMEA results for Severity, Occurrence and Detection.

\begin{tabular}{ccc}
\hline $\mathbf{S}$ & $\mathbf{O}$ & $\mathbf{D}$ \\
\hline 0.0060 & 0.0353 & 0.0060 \\
0.0353 & 0.0353 & 0.0017 \\
0.0715 & 0.0715 & 0.0041 \\
0.0015 & 0.0313 & 0.0313 \\
0.0017 & 0.0114 & 0.0114 \\
0.0023 & 0.0756 & 0.0064 \\
0.0353 & 0.0633 & 0.0353 \\
0.0715 & 0.1520 & 0.0715 \\
0.0353 & 0.0353 & 0.0789 \\
0.1520 & 0.0041 & 0.0715 \\
0.0353 & 0.0633 & 0.0633 \\
0.0064 & 0.0756 & 0.0064 \\
0.0789 & 0.0353 & 0.0114 \\
0.0013 & 0.0715 & 0.0013 \\
0.0633 & 0.0114 & 0.0633 \\
0.0633 & 0.0633 & 0.0633 \\
0.0060 & 0.0353 & 0.0353 \\
0.0353 & 0.0353 & 0.0353 \\
0.1496 & 0.1496 & 0.1496 \\
\hline
\end{tabular}

Step 6. Obtain the PFDA-FMEA index. Table 4 values are blended in the mathematical product of PFDAFMEA $S, O$, and $D$, is giving us the PFDA-FMEA index in Table 5.

Table 5. PFDA-FMEA Results and risks ranking.

\begin{tabular}{cc}
\hline PFM ID & $\begin{array}{c}\text { PFDA-FMEA } \\
\text { Index }\end{array}$ \\
\hline PFM1 & $1.3 \mathrm{E}-06$ \\
PFM2 & $2.1 \mathrm{E}-06$ \\
PFM3 & $2.1 \mathrm{E}-05$ \\
PFM4 & $1.4 \mathrm{E}-06$ \\
PFM5 & $2.2 \mathrm{E}-07$ \\
PFM6 & $1.1 \mathrm{E}-06$ \\
PFM7 & $7.9 \mathrm{E}-05$ \\
PFM8 & $7.8 \mathrm{E}-04$ \\
PFM9 & $9.9 \mathrm{E}-05$ \\
PFM10 & $4.4 \mathrm{E}-05$ \\
PFM11 & $1.4 \mathrm{E}-04$ \\
PFM12 & $3.1 \mathrm{E}-06$ \\
\hline
\end{tabular}




\begin{tabular}{ll}
\hline PFM13 & $3.2 \mathrm{E}-05$ \\
PFM14 & $1.2 \mathrm{E}-07$ \\
PFM15 & $4.5 \mathrm{E}-05$ \\
PFM16 & $2.5 \mathrm{E}-04$ \\
PFM17 & $7.5 \mathrm{E}-06$ \\
PFM18 & $4.4 \mathrm{E}-05$ \\
PFM19 & $3.3 \mathrm{E}-03$ \\
\hline
\end{tabular}

Step 7. Determine the PFM ranking. The results are ranked to identify the PFM risks and to support on the decision to be taken. Table 6 show the PFM ranking.

Table6. PFDA-FMEA Results and risks ranking.

\begin{tabular}{ccc}
\hline PFM ID & $\begin{array}{c}\text { PFDA-FMEA } \\
\text { Index }\end{array}$ & $\begin{array}{c}\text { PFM } \\
\text { Ranking }\end{array}$ \\
\hline PFM1 & $1.3 \mathrm{E}-06$ & 16 \\
PFM2 & $2.1 \mathrm{E}-06$ & 14 \\
PFM3 & $2.1 \mathrm{E}-05$ & 11 \\
PFM4 & $1.4 \mathrm{E}-06$ & 15 \\
PFM5 & $2.2 \mathrm{E}-07$ & 18 \\
PFM6 & $1.1 \mathrm{E}-06$ & 17 \\
PFM7 & $7.9 \mathrm{E}-05$ & 6 \\
PFM8 & $7.8 \mathrm{E}-04$ & 2 \\
PFM9 & $9.9 \mathrm{E}-05$ & 5 \\
PFM10 & $4.4 \mathrm{E}-05$ & 8 \\
PFM11 & $1.4 \mathrm{E}-04$ & 4 \\
PFM12 & $3.1 \mathrm{E}-06$ & 13 \\
PFM13 & $3.2 \mathrm{E}-05$ & 10 \\
PFM14 & $1.2 \mathrm{E}-07$ & 19 \\
PFM15 & $4.5 \mathrm{E}-05$ & 7 \\
PFM16 & $2.5 \mathrm{E}-04$ & 3 \\
PFM17 & $7.5 \mathrm{E}-06$ & 12 \\
PFM18 & $4.4 \mathrm{E}-05$ & 9 \\
PFM19 & $3.3 \mathrm{E}-03$ & 1 \\
\hline & & \\
\hline
\end{tabular}

\section{Results and discussion}

This section explains the experiments performed to validate the results of the proposed method. Using 22 random experiments modifying the weights on the critical factors, Figure 2 show the consistency on the PFM rankings. 


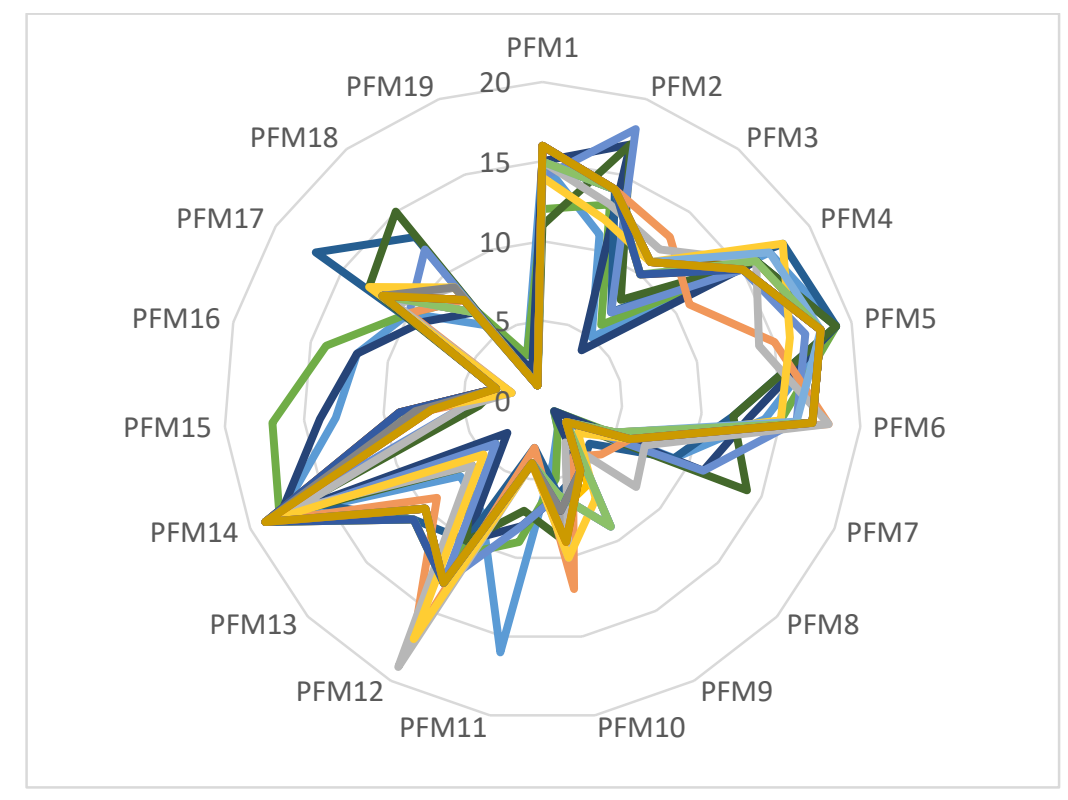

Figure 2. PFDA-FMEA Ranking - Sensibility Analysis.

Besides, in order to validate the method correlation and using same 22 random experiments, a correlation analysis shows a high correlation on most of the experiments. Table 7 show the results.

Table 6. Correlation Analysis

\begin{tabular}{|c|c|c|c|c|c|c|c|c|c|c|c|c|c|c|c|c|c|c|c|c|c|c|}
\hline & 1 & 2 & 3 & 4 & 5 & 6 & 7 & 8 & 9 & 10 & 11 & 12 & 13 & 14 & 15 & 16 & 17 & 18 & 19 & 20 & 21 & 22 \\
\hline Exp. 1 & 1.0 & & & & & & & & & & & & & & & & & & & & & \\
\hline Exp. 2 & 1.0 & 1.0 & & & & & & & & & & & & & & & & & & & & \\
\hline Exp. 3 & 1.0 & 1.0 & 1.0 & & & & & & & & & & & & & & & & & & & \\
\hline Exp. 4 & 1.0 & 1.0 & 1.0 & 1.0 & & & & & & & & & & & & & & & & & & \\
\hline Exp. 5 & 0.6 & 0.7 & 0.7 & 0.6 & 1.0 & & & & & & & & & & & & & & & & & \\
\hline Exp. 6 & 0.7 & 0.7 & 0.7 & 0.7 & 0.9 & 1.0 & & & & & & & & & & & & & & & & \\
\hline Exp. 7 & 0.7 & 0.7 & 0.7 & 0.7 & 0.9 & 0.9 & 1.0 & & & & & & & & & & & & & & & \\
\hline Exp. 8 & 1.0 & 1.0 & 1.0 & 1.0 & 0.7 & 0.7 & 0.7 & 1.0 & & & & & & & & & & & & & & \\
\hline Exp. 9 & 1.0 & 1.0 & 1.0 & 1.0 & 0.7 & 0.7 & 0.7 & 1.0 & 1.0 & & & & & & & & & & & & & \\
\hline Exp. 10 & 1.0 & 1.0 & 1.0 & 1.0 & 0.6 & 0.7 & 0.7 & 1.0 & 1.0 & 1.0 & & & & & & & & & & & & \\
\hline Exp. 11 & 0.9 & 0.9 & 0.9 & 0.9 & 0.6 & 0.6 & 0.7 & 0.9 & 0.9 & 0.9 & 1.0 & & & & & & & & & & & \\
\hline Exp. 12 & 0.8 & 0.8 & 0.8 & 0.8 & 0.6 & 0.6 & 0.7 & 0.8 & 0.8 & 0.8 & 0.9 & 1.0 & & & & & & & & & & \\
\hline Exp. 13 & 0.9 & 0.9 & 0.8 & 0.9 & 0.6 & 0.7 & 0.8 & 0.8 & 0.9 & 0.9 & 0.8 & 0.9 & 1.0 & & & & & & & & & \\
\hline Exp. 14 & 0.9 & 0.9 & 0.9 & 0.9 & 0.4 & 0.5 & 0.6 & 0.9 & 0.9 & 0.9 & 0.7 & 0.7 & 0.8 & 1.0 & & & & & & & & \\
\hline Exp. 15 & 0.9 & 0.9 & 0.9 & 0.9 & 0.4 & 0.5 & 0.6 & 0.9 & 0.9 & 0.8 & 0.7 & 0.7 & 0.8 & 0.9 & 1.0 & & & & & & & \\
\hline Exp. 16 & 0.9 & 0.9 & 0.9 & 0.9 & 0.6 & 0.6 & 0.7 & 0.9 & 0.9 & 0.9 & 0.8 & 0.8 & 0.9 & 0.9 & 0.9 & 1.0 & & & & & & \\
\hline Exp. 17 & 1.0 & 1.0 & 1.0 & 1.0 & 0.6 & 0.7 & 0.7 & 1.0 & 1.0 & 1.0 & 0.9 & 0.8 & 0.9 & 0.9 & 0.8 & 0.9 & 1.0 & & & & & \\
\hline Exp. 18 & 1.0 & 1.0 & 1.0 & 1.0 & 0.6 & 0.7 & 0.7 & 1.0 & 1.0 & 1.0 & 0.9 & 0.7 & 0.9 & 0.9 & 0.8 & 0.9 & 1.0 & 1.0 & & & & \\
\hline Exp. 19 & 1.0 & 1.0 & 1.0 & 1.0 & 0.7 & 0.7 & 0.7 & 1.0 & 1.0 & 1.0 & 0.9 & 0.8 & 0.8 & 0.9 & 0.9 & 0.9 & 1.0 & 1.0 & 1.0 & & & \\
\hline Exp. 20 & 1.0 & 1.0 & 1.0 & 1.0 & 0.6 & 0.7 & 0.7 & 1.0 & 1.0 & 1.0 & 0.9 & 0.8 & 0.9 & 0.9 & 0.9 & 0.9 & 1.0 & 1.0 & 1.0 & 1.0 & & \\
\hline Exp. 21 & 1.0 & 1.0 & 1.0 & 1.0 & 0.7 & 0.7 & 0.7 & 1.0 & 1.0 & 1.0 & 0.9 & 0.8 & 0.9 & 0.9 & 0.9 & 0.9 & 1.0 & 1.0 & 1.0 & 1.0 & 1.0 & \\
\hline Exp. 22 & 1.0 & 1.0 & 1.0 & 1.0 & 0.6 & 0.7 & 0.7 & 1.0 & 1.0 & 1.0 & 0.9 & 0.8 & 0.9 & 0.9 & 0.9 & 0.9 & 1.0 & 1.0 & 1.0 & 1.0 & 1.0 & 1.0 \\
\hline
\end{tabular}


In addition, a Cronbach's alpha was performed giving the 0.9924 , confirming the obtained results are consistent and confidence of the PFDA-FMEA method.

\section{Conclusions}

PFDA-FMEA is a harmonically integrated methodology that shore up Product Design, helping to clearly identify the risks of the PFM that tent to affect the design process. PFDA-FMEA method is removing the uncertain of the cross-functional team judgement and assessment because of the different point of views over the risk assessment, since Pythagorean Fuzzy Sets methodology is applied. Hence, PFDA-FMEA improves the RPN ranking while human judgment ambiguity is removed. This last is confirmed on the statistical analysis in the results section.

Conventional FMEA is enhanced using PFDA-FMEA integrated methodology, closing the current FMEA gaps mentioned in the introduction of this document and based on the Cronbach analysis the $99 \%$ of the confidence. Consequently PFDA-FMEA is making systematic mode to take the decision based on risks identified on Product Design evaluated by the PFMs. 


\section{References}

[1] K. B. Kahn, "NPD process formality across global regions," 2018.

[2] P. Stief, J. Dantan, A. Etienne, A. Siadat, and R. Birkelandsvei, "ScienceDirect ScienceDirect ScienceDirect Advancing evidence of stereotypes in Advancing empirical empirical evidence of iteration iteration stereotypes in the the fuzzy fuzzy front front end end of of product product development development processes pro," Procedia CIRP, vol. 91, pp. 61-70, 2020.

[3] I. O. P. C. Series and M. Science, "Product Development Analysis using Quality Function Deployment Product Development Analysis using Quality Function Deployment," 2020.

[4] M. Yang, J. Hu, and L. Huang, "Research of product innovative models based on QFD, TRIZ and DOE," 2010 IEEE 11th Int. Conf. Comput. Ind. Des. Concept. Des. CAID CD'2010, vol. 1, pp. 325-328, 2010.

[5] J. Braband, "Definition and Analysis of a New Risk Priority Number Concept," no. 0, 2004.

[6] H. Fang, J. Li, and W. Song, "Failure mode and effects analysis : an integrated approach based on rough set theory and prospect theory," Soft Comput., vol. 8, 2019.

[7] H. Liu, J. You, P. Li, and Q. Su, "Failure Mode and Effect Analysis Under Uncertainty : An Integrated Multiple Criteria Decision," vol. 65, no. 3, pp. 1380-1392, 2016.

[8] A. Pillay and J. Wang, "Modified failure mode and effects analysis using approximate reasoning," Elsevier Ocean Eng. Ser., vol. 7, no. C, pp. 149-177, 2003.

[9] Q. Zhou and V. V. Thai, "Fuzzy and grey theories in failure mode and effect analysis for tanker equipment failure prediction," Saf. Sci., vol. 83, pp. 74-79, 2016.

[10] H. Safari, Z. Faraji, and S. Majidian, "Identifying and evaluating enterprise architecture risks using FMEA and fuzzy VIKOR," 2014.

[11] K. P. L. Pun, J. Rotanson, C. W. Cheung, and A. H. S. Chan, "Application of fuzzy integrated FMEA with product lifetime consideration for new product development in flexible electronics industry," J. Ind. Eng. Manag., vol. 12, no. 1, pp. 176-200, 2019.

[12] S. M. Chen, S. H. Cheng, and T. C. Lan, "A new multicriteria decision making method based on the topsis method and similarity measures between intuitionistic fuzzy sets," Proc. - Int. Conf. Mach. Learn. Cybern., vol. 2, pp. 692-696, 2017.

[13] R. Balafshan, "Multi-objective mathematical model based on fuzzy hybrid and FMEA approach for the risks of oil and gas projects," 2020.

[14] L. A. Zadeh, I. Introduction, and U. S. Navy, "Fuzzy Sets * -," vol. 353, pp. 338-353, 1965.

[15] T. Atanassov, “Intuitionistic Fuzzy Sets," vol. 20, pp. 87-96, 1986.

[16] R. R. Yager and L. Fellow, "Pythagorean Membership Grades in Multicriteria Decision Making," vol. 22, no. 4, pp. 958-965, 2014.

[17] M. G. Wichmann, M. Gäde, and T. S. Spengler, "A fuzzy robustness measure for the scheduling of commissioned product development projects ${ }^{3}$," Fuzzy Sets Syst., vol. 377, pp. 125-149, 2019.

[18] L. Pérez-Domínguez, A. Alvarado-Iniesta, J. L. García-Alcaraz, and D. J. Valles-Rosales, "Intuitionistic fuzzy dimensional analysis for multi-criteria decision making ' '," Iran. J. Fuzzy Syst., vol. 15, no. July, pp. 47-70, 2018.

[19] J. F. Mahoney and S. Yeralan, "ScienceDirect ScienceDirect Dimensional Dimensional Analysis Analysis," Procedia Manuf., vol. 38, no. 2019, pp. 694-701, 2020. 
[20] W. Shen, K. Road, U. K. Sa, D. K. J. Lin, and C. J. Nachtsheim, "Dimensional Analysis and Its Applications in Statistics," pp. 1-19.

[21] P. Wolniak, B. Sauthoff, D. Kloock-Schreiber, and R. Lachmayer, "Automated Product Functionality and Design Optimization Instancing a Product-Service System," Proc. Des. Soc. Des. Conf., vol. 1, pp. 1405-1414, 2020.

[22] L. H. Chen and W. C. Ko, "Fuzzy linear programming models for new product design using QFD with FMEA," Appl. Math. Model., vol. 33, no. 2, pp. 633-647, 2009.

[23] J. Huang, Z. Li, and H. C. Liu, "New approach for failure mode and effect analysis using linguistic distribution assessments and TODIM method," Reliab. Eng. Syst. Saf., vol. 167, pp. 302-309, 2017.

[24] I. Mzougui and Z. El Felsoufi, "Proposition of a modified FMEA to improve reliability of product," Procedia CIRP, vol. 84, pp. 1003-1009, 2019.

[25] AIAG, "AIAG." [Online]. Available: https://www.aiag.org/. [Accessed: 19-Feb-2020].

[26] R. R. Yager, "Pythagorean fuzzy subsets," Proc. 2013 Jt. IFSA World Congr. NAFIPS Annu. Meet. IFSA/NAFIPS 2013, vol. 2, no. x, pp. 57-61, 2013.

[27] X. Zhang and Z. Xu, "Extension of TOPSIS to Multiple Criteria Decision Making with Pythagorean Fuzzy Sets," vol. 0, pp. 1-18, 2014.

[28] M. S. Yang and Z. Hussain, "Fuzzy entropy for Pythagorean fuzzy sets with application to multicriterion decision making," Complexity, vol. 2018, 2018.

[29] A. J. V. Silva, L. A. P. Dominguez, E. M. Gómez, A. Alvarado-Iniesta, and I. J. C. P. Olguín, "Dimensional analysis under pythagorean fuzzy approach for supplier selection,"

Symmetry (Basel)., vol. 11, no. 3, 2019. 